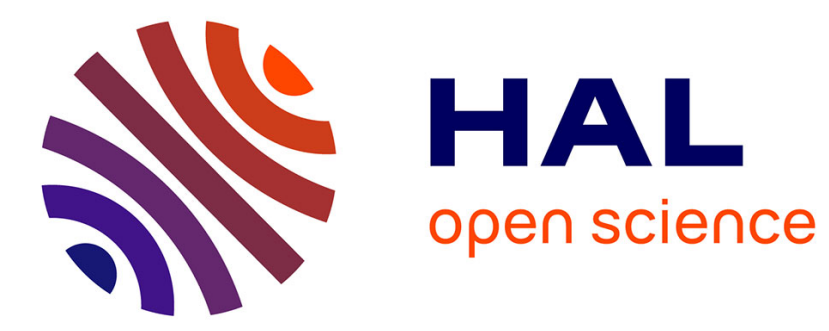

\title{
Numerical study on CNT nanofluids behavior in laminar pipe flow
}

\author{
A.A. Minea, P. Estellé
}

\section{To cite this version:}

A.A. Minea, P. Estellé. Numerical study on CNT nanofluids behavior in laminar pipe flow. Journal of Molecular Liquids, 2018, 271, pp.281-289. 10.1016/j.molliq.2018.08.161 . hal-01881087

\section{HAL Id: hal-01881087 \\ https://hal-univ-rennes1.archives-ouvertes.fr/hal-01881087}

Submitted on 28 Sep 2018

HAL is a multi-disciplinary open access archive for the deposit and dissemination of scientific research documents, whether they are published or not. The documents may come from teaching and research institutions in France or abroad, or from public or private research centers.
L'archive ouverte pluridisciplinaire HAL, est destinée au dépôt et à la diffusion de documents scientifiques de niveau recherche, publiés ou non, émanant des établissements d'enseignement et de recherche français ou étrangers, des laboratoires publics ou privés. 


\title{
Numerical study on CNT nanofluids behavior in laminar pipe flow
}

\author{
Alina Adriana MINEA ${ }^{1}$, Patrice ESTELLÉ ${ }^{2}$ \\ ${ }^{1}$ Technical University “Gheorghe Asachi” from Iasi, Bd. D. Mangeron no.63, Iasi, 700050, \\ Romania \\ aminea@tuiasi.ro \\ ${ }^{2}$ University of Rennes, LGCGM, EA3913, F-35000 Rennes, France
}

\begin{abstract}
This paper numerically investigates the heat transfer behavior of carbon nanotubes nanofluids under laminar forced flow in horizontal pipe. In order to describe better the nanofluids flow, the thermophysical properties were previously experimentally evaluated considering the influence of nanoparticle content and the effect of non-Newtonian nature of some nanofluids. In an original manner, this study was conceived considering a real experimental set-up with known boundary conditions for simulation validation. The results are presented and discussed for various Re numbers, in a wide range of 500-2000 and it was noticed that the convective heat transfer coefficient of nanofluids is better for low Re number and higher particle loading, while the nanofluid works in non-Newtonian flow. Additionally, an empirical correlation that relates $\mathrm{Nu}$ number to $\mathrm{Re}$, Pr and pipe location for all base fluids and nanofluids was proposed.
\end{abstract}

Keywords: CNT nanofluids; thermal conductivity; heat transfer; $\mathrm{Nu}$ number 


\section{Highlights}

- numerical study on CNT based nanofluids

- thermophysical properties were experimentally evaluated

- correlation was proposed in regard to $\mathrm{Nu}$ evaluation depending on $\mathrm{Re}$, Pr and pipe location 
$\mathrm{c}_{\mathrm{p}} \quad$ specific heat, $\mathrm{J} / \mathrm{KgK}$

D hydraulic diameter, $\mathrm{m}$

h heat transfer coefficient, $W / \mathrm{m}^{2} \mathrm{~K}$

$\mathrm{k}$ thermal conductivity, W/mK

L channel length. $\mathrm{m}$

m mass flux, $\mathrm{Kg} / \mathrm{sm}^{2}$

n power law index, -

$\mathrm{P} \quad$ dimensionless pressure, -

$\mathrm{p} \quad$ pressure, $\mathrm{Pa}$

Pr Prandtl number, -

$\mathrm{r} \quad$ radius, $\mathrm{m}$

$\mathrm{R}$ non-dimensional tube radius, -

Re Reynolds number, -

$\mathrm{T} \quad$ temperature, $\mathrm{K}$

q wall heat flux, $\mathrm{W} / \mathrm{m}^{2}$

$\mathrm{u}, \mathrm{v}, \mathrm{w} \quad$ velocity components, $\mathrm{m} / \mathrm{s}$

$\mathrm{u}_{\infty} \quad$ average velocity for inlet flow, $\mathrm{m} / \mathrm{s}$

U dimensionless tangential velocity, -

V dimensionless radial velocity, -

W dimensionless axial velocity, -

$\mathrm{x}, \mathrm{y}, \mathrm{z} \quad$ cartesian coordinates, $\mathrm{m}$

$\mathrm{X}, \mathrm{Y}, \mathrm{Z} \quad$ non-dimensional coordinates, -

\section{Greek symbols}

$\theta$

$\varphi$

$\gamma$

$\rho$

$\mu$

$\eta$

$\Theta$ cylindrical coordinate, ${ }^{\circ}$

volume concentration of nanoparticles, \%

shear rate, $1 / \mathrm{s}$

density, $\mathrm{Kg} / \mathrm{m}^{3}$

fluid dynamic viscosity, $\mathrm{Kg} / \mathrm{ms}$

consistency index, -

dimensionless temperature, - 


\section{Subscripts}

$\mathrm{b}$

bulk

bf

refers to base-fluid

eff

effective

$\mathrm{nf}$

refers to nanofluid

$\mathrm{p}$

particle

r refers to "nanofluid/base-fluid" ratio

W

wall 


\section{Introduction}

Flow and heat transfer through pipes under laminar conditions is encountered in many industrials situations and thermal systems. In this configuration, heat transfer of flowing liquids is generally achieved imposing constant temperature or constant heat flux at pipe wall. One way to improve thermal transport properties in pipes is to introduce nanoparticle of conductive material within common conventional fluids. This leads to what it is now well known as nanofluids. These new fluids received great attention over the last years [1-7] and their thermophysical properties were assessed in different conditions [1-3, 6, 7]. Plus, a lot of studies were dedicated to heat transfer performance evaluation $[4,5]$. For example, Sadri et al. [4] performed a successions of numerical simulations in order to predict the heat transfer performance of graphene based nanofluids and found a very good agreement between experimental and numerical procedures. On the other hand, the relevance of a numerical approach versus an experimental one was assessed also by Ghasemi et al. [5] and the conclusion was positive (deviation of $6 \%$ between numerical and experimental approach). In addition, they found that the nanofluid has significantly higher heat transfer coefficient than that of the base fluid, for the studied heat sink.

Among the large variety of available nanoparticle nature, carbon-based nanoparticles appear as very interesting because of high intrinsic thermal properties of this material. Several studies have been performed in the past to investigate and predict potential heat transfer characteristics of carbon-based nanofluids, and in particular for nanotubes dispersed in water, flowing under laminar regime in pipe.

Some experimental studies have been thus reported. Convective heat transfer (CHT) in laminar regime of carbon nanotubes aqueous nanofluids flowing in a horizontal pipe was firstly evaluated by Ding et al. [8] in Re range 800-1200. An enhancement in CHT was reported due to the presence of nanotubes depending on nanotube content, pipe location and Reynolds number. Flow properties of water-based CNT nanofluids through a horizontal tube were also investigated by Ko et al. [9] who evidence the increase of pressure drop under laminar regime in comparison with base fluid. Garg et al. [10] showed that CHT in horizontal tube under constant heat flux of CNT nanofluids slightly decreases with increasing of Re, in the range 600-1200, while it increases with axial distance. In the Re range 1000-2000, Meyer et al. [11] evidenced the CHT enhancement of MWCNT-water nanofluids compare to pure water. However, at same fluid velocity, CHT of nanofluids is lower than water due to high viscosity of nanofluids. Abreu et al. also did an experimental study [12]. They showed that $\mathrm{Nu}$ number increases with Re (1200-2100) and nanotubes content. However, Nu enhancement 
rate was lowered by the presence of nanotubes. CHT in uniformly heated copper tube of MWCNT/water nanofluids under laminar regime was also investigated by Gupta et al. [13]. They considered the influence of a constant velocity criteria in contrast to constant $\mathrm{Re}$ number, in the range $0.166-0.232 \mathrm{~m} / \mathrm{s}$ and nanoparticle content between 0.05 and 0.5 in wt.\%. They observed that for a fixed velocity, Re decreases with nanotubes content. At fixed concentration, heat transfer enhancement is not affected by velocity, maximum enhancement was obtained for the higher content in nanotubes. Hosseinipour et al. also performed experimental study with amino acid-functionalized MWCNT water-based nanofluids [14]. They evidenced that in laminar regime under constant heat flux, CHT was increased with both increase of $\operatorname{Re}(800-2000)$ and nanofluid concentration (0.1-0.2 mass \%), while pressure drop of nanofluids was not drastically increased due to low content in nanotubes.

Also, in less extend, numerical or theoretical works were also proposed considering in particular the non-Newtonian nature of CNT water nanofluids. CHT evaluation of $1 \%$ MWCNT-water nanofluid through a tube under laminar and constant heat flux conditions was performed by Kamali and Binesh [15] solving Navier-Stockes and energy equations from finite volume method. Results were favorably compared to experimental data and an increase in $\mathrm{Nu}$ number, higher than the one of water, was reported with Re increase in the range 6001200. Lastly, CHT in circular tube of MWCNT dispersed in a mixture of water and ethylene glycol was evaluated from theoretical correlations in [16], showing that heat transfer enhancement was improved with concentration and temperatures rise. It was noted that high velocity within the tube is preferable to increase heat transfer due to non-Newtonian nature of more concentrated nanofluids.

As a contribution of this topic, the aim of this case study is to investigate heat transfer behavior of carbon nanotubes nanofluids under laminar forced flow in horizontal pipe from numerical analysis. For that, thermophysical properties previously evaluated were used considering the influence of nanoparticle content and the effect of non-Newtonian nature of some nanofluids. In an original way, this study was also conceived considering a real experimental set-up with known boundary conditions for simulation purpose. The results are presented and discussed for various Re numbers, in a wide range of 500-2000. Finally, an empirical correlation that relates $\mathrm{Nu}$ number to $\mathrm{Re}$, $\mathrm{Pr}$ and pipe location for both base fluids and nanofluids was proposed.

\section{Thermophysical properties of CNT nanofluids}


Nanofluids considered here were previously investigated, more information about their preparation and stability, average dimension and properties of nanotubes can be found in [1720]. Here, only important details and results are given. Carbon nanotubes were dispersed in a base fluid composed of water and SDBS as surfactant, with a constant ratio between both components. Volume content of carbon nanotubes and SDBS used for nanofluid production are mentioned in Table 1. Note that a label is also included in Table 1 to differentiate each fluids in the following of the paper.

insert Table 1 here

Thermophysical properties of these nanofluids were evaluated in some papers in the temperature range $20-40^{\circ} \mathrm{C}$. While SDBS content penalizes and reduces thermal conductivity of water, it was reported that thermal conductivity of these nanofluids increases with both volume concentration and temperature [19]. Thermal conductivity enhancement of nanofluids is depicted by Figure 1 that clearly shows the influence of nanotube content and temperature. Results clearly shows that the thermal conductivity of nanofluids increased while adding nanoparticles and while temperature is increasing. This phenomenon is generally noticed for all nanofluids and is stronger for CNT based nanofluids due to high conductive nanoparticles. A maximum enhancement of about $40 \%$ was reported for $\mathrm{N} 3$ at $40^{\circ} \mathrm{C}$ and 0.278 vol.\%. The minimum increase in thermal conductivity, $4.5 \%$, was noticed at $20{ }^{\circ} \mathrm{C}$ for $\mathrm{N} 1$.

insert Figure 1 here

Density of nanofluids were also measured in the same temperature range and volume concentration [17]. Data were collected in Table 2. They evidence that density of water is increased with SDBS and CNT content, and that both densities of base fluid and nanofluids decrease with temperature. Heat capacity of base fluids and nanofluids was also evaluated from theoretical relationship [17], values are also indicated in Table 2.

insert Table 2 here

insert Table 3 here

insert Table 4 here 
Finally, the rheological behavior of base fluids and nanofluids was studied in $[17,20]$. It was shown that base fluids behave as Newtonian fluids while nanofluids behavior depends on nanotube content and temperature as indicated in Table 3. To model the non-Newtonian shear-thinning behavior of some nanofluids, Power-Law equation, given by equation (1), was used. Parameters extracted from this model are also included in Table 4.

$\mu=\eta \gamma^{\mathrm{n}-1}$,

where $\mu$ is the viscosity, $\gamma$ is the shear rate, $\eta$ is the consistency index and $n$ is the power law index.

Table 2 and Figure 2 show that viscosity of base fluids slightly decreases with surfactant content. Moreover, the viscosity of base fluids exhibit lower values at higher temperatures. With regards of nanofluids, viscosity is increased with nanotube content and decreases with temperature as usually reported. Anyway, if one considers a shear rate of $1000 \mathrm{1} / \mathrm{s}$, the relative viscosity variation with temperature for CNT nanofluids is illustrated in Figure 3. Relative viscosity increase is varying from $3-87 \%$ depending on CNT volume concentration, temperature and base fluid.

insert Figure 2 here

insert Figure 3 here

All these properties were considered in the following to model and predict heat transfer behavior of nanofluids under laminar forced flow in horizontal pipe. Numerical analysis and pipe configuration presently used are described in the next section.

\section{Numerical procedure}

In this study, the CFD models are considered for fully developed laminar flow in a uniformly heated tube based on single-phase model with experimentally determined properties, as mentioned before.

\subsection{Numerical set-up}

The numerical approach involves a steady and laminar forced flow combined with heat transfer of CNT based nanofluids inside a tube with a diameter of $0.008 \mathrm{~m}$ and $2 \mathrm{~m}$ length with several different heated zones [21], as shown in Figure 4. As one can see in Figure 4, both the inlet and outlet zone have $0.125 \mathrm{~m}$ in length and each interior zone has a length of 
$0.25 \mathrm{~m}$. The fluid inlet temperature is maintained constant at $19.57^{\circ} \mathrm{C}$ and the Reynolds number $(\mathrm{Re})$ was varied from 500 to 2000.

The system of partial differential equations (see eq. (2)-(5)) used to numerically simulate the nanofluids heat transfer behavior is described in detail in [22]. The CFD code used for this analysis is Ansys Fluent [23] and more information on laminar modelling and the set of equations can be found in [22].

insert Figure 4 here

Continuity equation:

$\frac{1}{\mathrm{R}} \frac{\partial}{\partial \theta}\left(\rho_{\mathrm{nf}} \mathrm{U}\right)+\frac{1}{\mathrm{R}} \frac{\partial}{\partial \mathrm{R}}\left(\rho_{\mathrm{nf}} \mathrm{RV}\right)+\frac{\partial}{\partial \mathrm{z}}\left(\rho_{\mathrm{nf}} \mathrm{W}\right)=0$.

Momentum equation on $\mathrm{R}$ direction:

$\frac{1}{\mathrm{R}} \frac{\partial}{\partial \theta}\left(\rho_{\mathrm{nf}} \mathrm{UV}\right)+\frac{1}{\mathrm{R}} \frac{\partial}{\partial \mathrm{R}}\left(\rho_{\mathrm{nf}} \mathrm{RVV}\right)+\frac{\partial}{\partial \mathrm{z}}\left(\rho_{\mathrm{nf}} \mathrm{WV}\right)-\frac{1}{\mathrm{R}}\left(\rho_{\mathrm{nf}} \mathrm{U}^{2}\right)=$
$=-\frac{1}{\mathrm{R}} \frac{\partial \mathrm{P}}{\partial \theta}+\frac{1}{\mathrm{R}^{2}} \frac{\partial}{\partial \theta}\left(\mu_{\mathrm{nf}} \frac{\partial \mathrm{V}}{\partial \theta}\right)+\frac{\partial}{\partial \mathrm{R}}\left(\frac{\mu_{\mathrm{nf}}}{\mathrm{R}} \frac{\partial(\mathrm{RV})}{\partial \mathrm{R}}\right)-\frac{2 \mu_{\mathrm{nf}}}{\mathrm{R}^{2}} \frac{\partial \mathrm{U}}{\partial \theta}$.

Energy equation:

$$
\begin{aligned}
& \frac{1}{\mathrm{R}} \frac{\partial}{\partial \theta}\left(\rho_{\mathrm{nf}} \mathrm{U} \Theta\right)+\frac{1}{\mathrm{R}} \frac{\partial}{\partial \mathrm{R}}\left(\rho_{\mathrm{nf}} \mathrm{RV} \Theta\right)+\frac{\partial}{\partial \mathrm{z}}\left(\rho_{\mathrm{nf}} \mathrm{W} \Theta\right)= \\
& =\frac{1}{\mathrm{R}^{2}} \frac{\partial}{\partial \theta}\left(\frac{\mathrm{k}_{\mathrm{nf}}}{\mathrm{c}_{\mathrm{pnf}}} \frac{\partial \Theta}{\partial \theta}\right)+\frac{\partial}{\mathrm{R} \partial \mathrm{R}}\left(\mathrm{R} \frac{\mathrm{k}_{\mathrm{nf}}}{\mathrm{c}_{\mathrm{pnf}}} \frac{\partial \Theta}{\partial \mathrm{R}}\right)
\end{aligned}
$$

Where the nondimensional variables are defined as:

$$
\mathrm{R}=\frac{\mathrm{r}}{\mathrm{D}}, \mathrm{Z}=\frac{\mathrm{Z}}{\mathrm{D}}, \mathrm{U}=\frac{\mathrm{u}}{\mathrm{u}_{\infty}}, \mathrm{V}=\frac{\mathrm{v}}{\mathrm{u}_{\infty}}, \mathrm{W}=\frac{\mathrm{w}}{\mathrm{u}_{\infty}}, \Theta=\frac{\mathrm{T}-\mathrm{T}_{\infty}}{\mathrm{T}_{\mathrm{w}}-\mathrm{T}_{\infty}}, \mathrm{P}=\frac{\mathrm{p}}{\rho \mathrm{u}_{\infty}^{2}} .
$$

In these equations, $\rho_{\mathrm{nf}}, \mu_{\mathrm{nf}}, \mathrm{C}_{\mathrm{nf}}$, and $\mathrm{k}_{\mathrm{nf}}$ are density, viscosity, heat capacity, and thermal conductivity of nanofluid, respectively. These values were replaced by the ones of base fluid to also model their flow properties within the tube.

The system of equations was solved using the control volume approach that converts the governing equations to another system of algebraic equations that can be easily solved by numerical approach. So, a second order upwind method was adopted for diffusive and convective terms, while pressure and velocity were coupled using SIMPLE (Semi Implicit Method for Pressure Linked Equations). 
All the fluids were subjected to a developed velocity at the tube entrance. As some nanofluids behave in non-Newtonian manner, their velocity fields were determined from the generalized Reynolds number valid for non-Newtonian introduced by Metzner and Reed [24]:

$$
\operatorname{Re}=\frac{\rho D^{n} u^{2-n}}{K((3 n+1) /(4 n))^{n} 8^{n-1}} .
$$

The flow velocity at inlet of the tube was estimated with the help of equation (6) with every data from Tables 3 and 4 and imposed Re values. Note that equation (6) reduces to Re number common expression of Newtonian fluid for $n=1$.

\subsection{Boundary conditions}

It was assumed that a developed flow with constant temperature enters the test section. Heat flux along the length of the pipe has been previously determined in Colla et al. [21] and it is used as a boundary condition for the numerical study. Here it can underlie that the heat flux imposed in [21] was not constant along the pipe and its values are depicted in Table 5. Result of simulation are temperatures at 8 locations along the wall, which have also been measured experimentally in [21]. An overview of boundary conditions are in Table 5.

insert Table 5 here

\section{- momentum conservation}

- $\quad$ at inlet: a developed velocity profile; prior simulation is necessary to estimate the profile and/or in laminar case

- $\quad$ at wall: no-slip boundary condition (flow velocity is zero)

- at outlet: constant static pressure is known. Can be chosen arbitrarily, i.e. relative pressure is zero

- energy conservation

- $\quad$ at inlet: constant temperature is known

- $\quad$ at wall: heat flux is known

- $\quad$ at outlet: not necessary, i.e. convective outflow boundary conditions is used

\subsection{Validation of the present discussion}

For grid validation, several meshes were built and for a better accuracy of results with less computational effort, the nodes were finer at the inlet and near the tube walls where 
temperature gradients are higher. For validation of the present study the numerical solution was confirmed by running a first case using pure water inside the flow configuration defined in Figure 4 and by comparing the results with previously outcomes available from literature [21].

The comparison of numerical analysis with the experimental data extracted from Colla et al. [21] is shown in Figure 5. As one can see from Figure 5, there is a very good agreement between the experimental data and the numerical model in terms of wall temperatures. The differences are between 0.11 and 0.22 degrees for each position. Thus, the model can be used for the current case study.

insert Figure 5 here

\section{Results and discussion}

\subsection{Heat transfer performance}

After confirming that the numerical model can generate accurate results, all the six fluids and nanofluids were analyzed at various Reynolds numbers in the range of 500-2000. The heat transfer performance of flowing fluids was defined in terms of convective local heat transfer coefficient (h):

$$
\mathrm{h}=\frac{\mathrm{q}}{\mathrm{T}_{\mathrm{w}}-\mathrm{T}_{\mathrm{m}}}
$$

where $\mathrm{q}$ is the heat flux, $\mathrm{T}_{\mathrm{w}}$ is the pipe wall temperature at a given location along the pipe and $\mathrm{T}_{\mathrm{m}}$ is the mean temperature in the pipe at the location where $\mathrm{T}_{\mathrm{w}}$ is defined. For this study, the convective heat transfer coefficient was evaluated at different points along the tube length.

Figure 6 and 7 gives some of the results from computational analysis at a distance $x=1.875$ $\mathrm{m}$, at the end of the pipe where the temperature is higher. The figure reveals an increase of the heat transfer coefficient with both an increase of Re and by adding nanoparticles to the base fluid (see Figure 7).

\section{insert Figure 6 here}

If it looks to Figure 6 it can be noted that at $\mathrm{Re}=500$, all the base fluids have almost the same heat transfer coefficient, that increases with the Re increase. Some minor differences (around 5-6\%) are noticed between B1 and B3 in terms of convective heat transfer. So, a lower 
percentage of SDBS is better than a very high one, even if the differences are not notable. This is explained by the decrease in both thermal conductivity and viscosity of base fluids when SDBS content is increased [19]. As a general outline, Re greatly influences (around 67 $\%$ increase in convective heat transfer coefficient) the heat transfer augmentation despite of the fluid composition.

\section{insert Figure 7 here}

Figure 7 shows the behavior at heating in different laminar flows for the CNT nanofluids and one can say that if Re increases, nanofluids performs better in terms of heat transfer. Also, the heat transfer coefficient is higher as the CNT volume concentration increases. The only exception is $\mathrm{N} 1$ that has a different rheological behavior (i.e. N1 is a Newtonian fluid) than other two nanofluids, as was explained in detail earlier.

Heat transfer enhancement for considered CNT nanofluids in connection with their specific base fluid is shown in Figure 8 and it is defined as:

$\mathrm{h}_{\mathrm{r}}=\frac{\mathrm{h}_{\mathrm{nf}}}{\mathrm{h}_{\mathrm{bf}}}$.

\section{insert Figure 8 here}

Plus, in Figure 9 is shown the heat transfer enhancement at another pipe location, at $\mathrm{x}=0.125$ i.e. close to the entrance region of the pipe. One can notice a smaller enhancement closer to the tube entrance. However, at the location close to the flow entrance, the Reynolds number influence on heat transfer enhancement is lower, in comparison to exit region of the pipe, as one can notice from Figure 9.

insert Figure 9 here

Figure 8 clearly shows the heat transfer enhancement over the base fluids and the net advantages of using CNT nanofluids. The maximum increase in heat transfer performance is noticed at low Reynolds numbers and it remains almost constant for Re greater than 1000 . Anyway, for almost all nanofluids was noticed an increase in convective heat transfer while adding small volume concentrations of CNT. N2 and N3 behaves similar for Re > 1000 while at low Re numbers N3 have a better heat transfer performance. N1 nanofluid heat transfer 
enhancement capability remains almost constant with $\mathrm{Re}$ variation. As an outline, all nanofluids have a heat transfer enhancement of at least $2 \%$ for $\operatorname{Re}<1000$ and for $\operatorname{Re}>1000$, nanofluids $\mathrm{N} 1, \mathrm{~N} 2$ and $\mathrm{N} 3$ get a heat transfer augmentation of min $6 \%$ in comparison with each base fluid.

Summarizing, the change in heat transfer coefficient enhancement at two different axial locations, $\mathrm{x} / \mathrm{D}=234.375$ and $\mathrm{x} / \mathrm{D}=15.625$, is presented in Figures 8 and 9 for Reynolds numbers varying between 500 and 2000, and a more pronounced increase is observed as the flow develops. These findings are in contradiction with conclusions drawn by Ilhan and Ertürk [25]. The complete data are presented in Figure 10 that confirms the explanations sketched earlier.

Furthermore, the authors tried to correlate all the numerical results and to present them in terms of $\mathrm{Nu}$ evolution in function of (location in pipe/(D Re Pr)), where Pr number is defined as the ratio of momentum diffusivity to thermal diffusivity:

$\operatorname{Pr}=\frac{\mathrm{c}_{\mathrm{p}} \mu}{\mathrm{k}}$.

Figure 10 summarizes all the findings for all fluids. In such a representation, all data collapse in single master curve where $\mathrm{Nu}$ decreases with the ratio $\mathrm{x} /(\mathrm{D} \operatorname{Re} \mathrm{Pr})$ that allow a correlation based on an exponential trendline to be obtained. As one can notice in Figure 10, a very well fitted trendline was obtained, with an $\mathrm{R}$-squared value $\mathrm{R}^{2}=0.93$ :

$$
\mathrm{Nu}=1.54\left(\frac{\mathrm{x}}{\mathrm{D} \operatorname{Re} \operatorname{Pr}}\right)^{-0.202},
$$

where $\mathrm{Nu}$ is defined as:

$\mathrm{Nu}=\frac{\mathrm{hD}}{\mathrm{k}}$.

insert Figure 10 here

\section{Conclusion}

In this study, heat transfer behavior of carbon nanotubes nanofluids under laminar forced flow in horizontal pipe was investigated from numerical analysis in range of Re number 500-2000. To be close to practical situation, a real experimental set-up with known boundary conditions was used for simulation purpose as well as thermophysical properties previously evaluated. First, main results about thermal conductivity and viscosity of both base fluids and nanofluids 
were presented. Then, simulation results were shown considering the effect of Re number, nanoparticle loading in comparison of base fluids, and pipe location on the convective heat transfer (CHT) enhancement. So, it was observed that CHT of nanofluids is better for low Re number and higher particle loading, while the nanofluid behaves in non-Newtonian manner. More relevant enhancement produced at the exit region of the pipe. Finally, an empirical correlation that relates $\mathrm{Nu}$ number to $\mathrm{Re}, \mathrm{Pr}$ and pipe location for both base fluids and nanofluids was proposed.

\section{Acknowledgments}

The authors would like to acknowledge that this research was possible within the COST action CA 15119: Nanouptake - Overcoming Barriers to Nanofluids Market Uptake. 


\section{References}

[1] M. Keyvani, M. Afrand, D. Toghraie, M. Reiszadeh, An experimental study on the thermal conductivity of cerium oxide/ethylene glycol nanofluid: developing a new correlation, Journal of Molecular Liquids 266 (2018) 211-217.

[2] P. K. Das, A review based on the effect and mechanism of thermal conductivity of normal nanofluids and hybrid nanofluids, Journal of Molecular Liquids 240 (2017) $420-446$.

[3] M. H. Ahmadi, A. Mirlohi, M. A. Nazari, R. Ghasempour, A review of thermal conductivity of various nanofluids, Journal of Molecular Liquids 265 (2018) 181-188.

[4] R. Sadri, A.R. Mallah, M. Hosseini, G. Ahmadi, S.N. Kazi, A. Dabbagh, C.H. Yeong, R. Ahmad, N.A. Yaakup, CFD modeling of turbulent convection heat transfer of nanofluids containing green functionalized graphene nanoplatelets flowing in a horizontal tube: Comparison with experimental data, Journal of Molecular Liquids 269 (2018) 152-159.

[5] S. E. Ghasemi, A.A. Ranjba, M.J. Hosseini, Forced convective heat transfer of nanofluid as a coolant flowing through a heat sink: Experimental and numerical study, Journal of Molecular Liquids 248 (2017) 264-270.

[6] A. B. Harooni, A. Najafi-Marghmaleki, A. Mohebbi, A. H. Mohammadi, On the estimation of viscosities of Newtonian nanofluids, Journal of Molecular Liquids 241 (2017) 1079-1090.

[7] A. Aminian, Predicting the effective viscosity of nanofluids for the augmentation of heat transfer in the process industries, Journal of Molecular Liquids 229 (2017) 300308.

[8] Y. Ding, H. Alias, D. Wen, R.A. Williams, Heat transfer of aqueous suspensions of carbon nanoubes (CNT nanofluids), Int. J. Heat Mass Transfer 49 (2006) 240-250.

[9] G.H. Ko, K. Heo, K. Lee, D.S. Kim, C. Kim, Y. Sohn, M. Choi, An experimental study of the pressure drop of nanofluids containing carbon nanotubes in a horizontal tube, Int. J. Heat Mass Transfer 50 (2007) 4749-4753.

[10] P. Garg, L.A. Jorge, C. Marsh, T.A. Carlson, D.A. Kessler, K. Annamalai, An experimental study on the effect of ultrasonication on viscosity and heat transfer performance of multi-wall carbon nanotube-based aqueous nanofluids, Int. J. Heat Mass Transfer 52 (2009) 5090-5101. 
[11] J.P. Meyer, T.J. McKrell, K. Grote, The influence of multi-walled carbon nanotubes on single-phase heat transfer and pressure drop characteristics in the transitional flow regime of smooth tubes. Int. J. Heat Mass Transf. 58 (2013) 597-609.

[12] B. Abreu, B. Lamas, A. Fonseca, N. Martins, M.S.A. Oliveira, Experimental characterization of convective heat transfer with MWCNT based nanofluids under laminar conditions, Heat Mass Transfer 50 (2014) 65-74.

[13] M. Gupta, R. Kumar, N. Arora, S. Kumar, N. Dilbagi, Forced convective heat transfer of MWCNT/Water nanofluid under constant heat flux: An experimental investigation, Arab. J. Sci. Eng., 41 (2016) 599-609.

[14] E. Hosseinipour, S.Z. Heiris, M. Shanbedi, Experimental investigation of pressure drop and heat transfer performance of amino-functionalized MWCNT in the circular tube, J. Therm. Anal. Calorim. 124 (2016) 205-214.

[15] R. Kamali, A.R. Binesh, Numerical investigation of heat transfer enhancement using carbon nanotube-based non-Newtonian nanofluid, Int. Com. Heat Mass Transf. 37 (2010) 1153-1157.

[16] E. Shahsavani, M. Afrand, R. Kalbasi, Unsing experimental data to estimate the heat transfer and pressure drop of non-Newtonian nanofluid flow through a circular tube: Applicable for use in heat exchangers, App. Therm. Eng. 129 (2018) 1573-1581.

[17] S. Halelfadl, T. Maré, P. Estellé, Efficiency of carbon nanotubes water based nanofluids as coolants, Experimental Thermal and Fluid Science 53 (2014) 104-110.

[18] P. Estellé, O. Mahian, T. Maré, H. Oztop, Natural convection of CNT water-based nanofluids in a differentially heated square cavity, J. Therm. Anal. Calorim. 128 (2017) 1765-1770.

[19] P. Estellé, S. Halelfadl, T. Maré, Thermal conductivity of CNT water based nanofluids: experimental trends and models overview, J. Therm. Eng., 1 (2015) 381390.

[20] S. Halelfadl, P. Estellé, B. Aladag, N. Doner, T. Maré, Viscosity of carbon nanotubes water-based nanofluids: Influence of concentration and temperature, Int. J. Therm. Sci. 71 (2013) 111-117.

[21] A.A. Minea, Uncertainties in modeling thermal conductivity of laminar forced convection heat transfer with water alumina nanofluids, Int. J. Heat Mass Trans. 68 (2014) 78-84.

[22] ANSYS FLUENT 14.1 code, ANSYS Inc. 
[23] L. Colla, L. Fedele, and M. H. Buschmann. Laminar mixed convection of TiO2-water nanofluid in horizontal uniformly heated pipe flow. Int. J. Therm. Sci., 97 (2015) 2640.

[24] A.B. Metzner, J. C. Reed, Flow of non-Newtonian fluids - correlation of the laminar, transition and turbulent-flow regions. AIChE J. 1(4) (1955) 434-440.

[25] B. Ilhan, H. Ertürk, Experimental characterization of laminar forced convection of hBN-water nanofluid in circular pipe, International Journal of Heat and Mass Transfer 111 (2017) 500-507 


\section{Tables and Figures caption}

Table 1. Labels used to differentiate each fluid over the numerical study

Table 2 Thermophysical properties of studied fluids: data extracted from [17-20]

Table 3. Rheological behavior of studied CNT nanofluids [17, 18, 20]

Table 4. Viscosity estimation (consistency and power law indexes) of studied non-Newtonian fluids $[17,18,20]$

Table 5: Experimental values extracted from Colla et al. [23]

Figure 1. Thermal conductivity enhancement of the CNT nanofluids.

Figure 2. Viscosity of the base fluids (water + SDBS surfactants) at different temperatures

Figure 3. Viscosity variation of the CNT nanofluids over their base fluids.

Figure 4. The calculation domain

Figure 5. Validation of present discussion

Figure 6. Heat transfer coefficient at $\mathrm{x}=1.875 \mathrm{~m}$ from inlet for the base fluids

Figure 7. Heat transfer coefficient at $\mathrm{x}=1.875 \mathrm{~m}$ from inlet for the CNT nanofluids

Figure 8. Heat transfer enhancement by adding CNT at the defined base fluids, for a location $\mathrm{x}=1.875 \mathrm{~m}$ in the pipe.

Figure 9. Heat transfer enhancement by adding CNT at the defined base fluids at a location $\mathrm{x}=0.125 \mathrm{~m}$

Figure 10. Nu number versus (x / D Re Pr) for all studied fluids - correlation 
Table 1. Labels used to differentiate each fluid over the numerical study

\begin{tabular}{|l|l|l|}
\hline & $\begin{array}{l}\text { short name to be } \\
\text { used in this paper }\end{array}$ & SDBS and CNT volume concentration, in vol. \% \\
\hline Base fluid 1 & B1 & $0.0169 \%$ SDBS \\
\hline Base fluid 2 & B2 & $0.338 \%$ SDBS \\
\hline Base fluid 3 & B3 & $0.847 \%$ SDBS \\
\hline Nanofluid 1 & N1 & 0.0055 CNT+0.0169 \% SDBS \\
\hline Nanofluid 2 & N2 & $0.111 \% \mathrm{CNT}+0.338 \%$ SDBS \\
\hline Nanofluid 3 & N3 & $0.278 \%$ CNT + 0.847 \% SDBS \\
\hline
\end{tabular}


Table 2 Thermophysical properties of studied fluids: data extracted from [17-20]

\begin{tabular}{|c|c|c|c|c|c|c|}
\hline \multicolumn{7}{|c|}{ Viscosity, $\mathrm{N}-\mathrm{s} / \mathrm{m}^{2}$} \\
\hline \multirow{2}{*}{$\begin{array}{l}\mathbf{T}, \\
{ }^{\circ} \mathbf{C}\end{array}$} & \multicolumn{3}{|c|}{ base fluid with SDBS } & \multicolumn{3}{|c|}{ nanofluid with CNT } \\
\hline & B1 & B2 & B3 & N1 & $\mathrm{N} 2$ & N3 \\
\hline 20 & 0.00103 & 0.00105 & 0.00108 & 0.00110 & $\begin{array}{l}\text { non- } \\
\text { Newtonian }\end{array}$ & non-Newtonian \\
\hline 30 & 0.00078 & 0.00079 & 0.00083 & 0.00080 & $\begin{array}{l}\text { non- } \\
\text { Newtonian }\end{array}$ & non-Newtonian \\
\hline 40 & 0.00063 & 0.00064 & 0.00065 & 0.00066 & $\begin{array}{l}\text { non- } \\
\text { Newtonian }\end{array}$ & non-Newtonian \\
\hline \multicolumn{7}{|c|}{ Thermal conductivity, W/m-K } \\
\hline \multirow[b]{2}{*}{$\mathbf{T},{ }^{\circ} \mathbf{C}$} & \multicolumn{3}{|c|}{ base fluid with SDBS } & \multicolumn{3}{|c|}{ nanofluid with CNT } \\
\hline & B1 & B2 & B3 & N1 & $\mathrm{N} 2$ & $\mathrm{~N} 3$ \\
\hline 20 & 0.581 & 0.5812 & 0.5659 & 0.6068 & 0.6238 & 0.6544 \\
\hline 30 & 0.6044 & 0.5903 & 0.5799 & 0.6718 & 0.7195 & 0.7624 \\
\hline 40 & 0.6199 & 0.6111 & 0.6004 & 0.7118 & 0.7833 & 0.8355 \\
\hline \multicolumn{7}{|c|}{ Density, $\mathrm{kg} / \mathrm{m}^{3}$} \\
\hline \multirow[b]{2}{*}{$\mathbf{T},{ }^{\circ} \mathbf{C}$} & \multicolumn{2}{|c|}{ base fluid with SDBS } & & \multicolumn{3}{|c|}{ nanofluid with CNT } \\
\hline & B1 & B2 & B3 & N1 & $\mathrm{N} 2$ & N3 \\
\hline 20 & 998.243 & 998.93 & 1000.03 & 1000.53 & 1002.39 & 1004.64 \\
\hline 30 & 995.674 & 997.45 & 996.84 & 998.20 & 1001.42 & 1003.88 \\
\hline 40 & 992.23 & 993.04 & 992.76 & 995.499 & 997.95 & 1000.22 \\
\hline \multicolumn{7}{|c|}{ Specific heat, J/kg-K } \\
\hline \multirow[b]{2}{*}{$\mathbf{T},{ }^{\circ} \mathbf{C}$} & \multicolumn{2}{|c|}{ base fluid with SDBS } & & \multicolumn{3}{|c|}{ nanofluid with CNT } \\
\hline & B1 & $\mathrm{B} 2$ & B3 & N1 & $\mathrm{N} 2$ & N3 \\
\hline 20 & 4182 & 4182 & 4182 & 4181.65 & 4178.09 & 4172.186 \\
\hline 30 & 4178 & 4178 & 4178 & 4177.65 & 4174.088 & 4168.179 \\
\hline 40 & 4179 & 4179 & 4179 & 4178.65 & 4175.087 & 4169.178 \\
\hline
\end{tabular}


Table 3. Rheological behavior of studied CNT nanofluids $[17,18,20]$

\begin{tabular}{|l|l|}
\hline Code & flow type, extracted from $[17,18,20]$ \\
\hline N1 & newtonian \\
\hline N2 & non-newtonian \\
\hline N3 & non-newtonian \\
\hline
\end{tabular}


Table 4. Viscosity estimation (consistency and power law indexes) of studied non-Newtonian fluids $[17,18,20]$

\begin{tabular}{|l|c|c|c|c|c|c|}
\hline \multirow{2}{*}{} & \multicolumn{6}{|c|}{ Temperature } \\
\cline { 2 - 7 } & \multicolumn{2}{|c|}{$20\left({ }^{\circ} \mathrm{C}\right)$} & \multicolumn{2}{|c|}{$30\left({ }^{\circ} \mathrm{C}\right)$} & \multicolumn{2}{c|}{$40\left({ }^{\circ} \mathrm{C}\right)$} \\
\cline { 2 - 7 } & $\eta$ & $\mathrm{n}$ & $\eta$ & $\mathrm{n}$ & $\eta$ & $\mathrm{n}$ \\
\hline $\mathrm{N} 2$ & 0.002 & 0.963 & 0.0013 & 0.949 & 0.0011 & 0.931 \\
\hline $\mathrm{N} 3$ & 0.0034 & 0.924 & 0.003 & 0.902 & 0.0026 & 0.878 \\
\hline
\end{tabular}


Table 5: Experimental values extracted from Colla et al. [23]

\section{inlet}

mass flux, $\mathrm{m}=0.0061151 \mathrm{~kg} / \mathrm{s}$

bulk temperature at inlet, $\mathrm{T}_{\mathrm{in}}=19.57^{\circ} \mathrm{C}$

water properties at inlet: $\rho=998.295 \mathrm{~kg} / \mathrm{m}^{3}, \mathrm{k}=0.597685 \mathrm{~W} / \mathrm{mK}$,

$c_{p}=4184.36 \mathrm{~J} / \mathrm{kgK}, \mu=1.012429 \cdot 10^{-3} \mathrm{Pas}$

Reynolds number at inlet, $\operatorname{Re}=\frac{4 \dot{\mathrm{m}}}{\pi \mathrm{d} \mu}=961.4$

\section{outlet}

bulk temperature at outlet, $\mathrm{T}=27.38^{\circ} \mathrm{C}$

power $[W]$

\begin{tabular}{|l|l|l|l|l|l|l|l|l|}
\hline P0-1 & P1-2 & P2-3 & P3-4 & P4-5 & P5-6 & P6-7 & P7-8 & P8-9 \\
\hline 12.6 & 25.2 & 25.2 & 25.2 & 25.0 & 24.9 & 24.9 & 24.8 & 12.4 \\
\hline
\end{tabular}




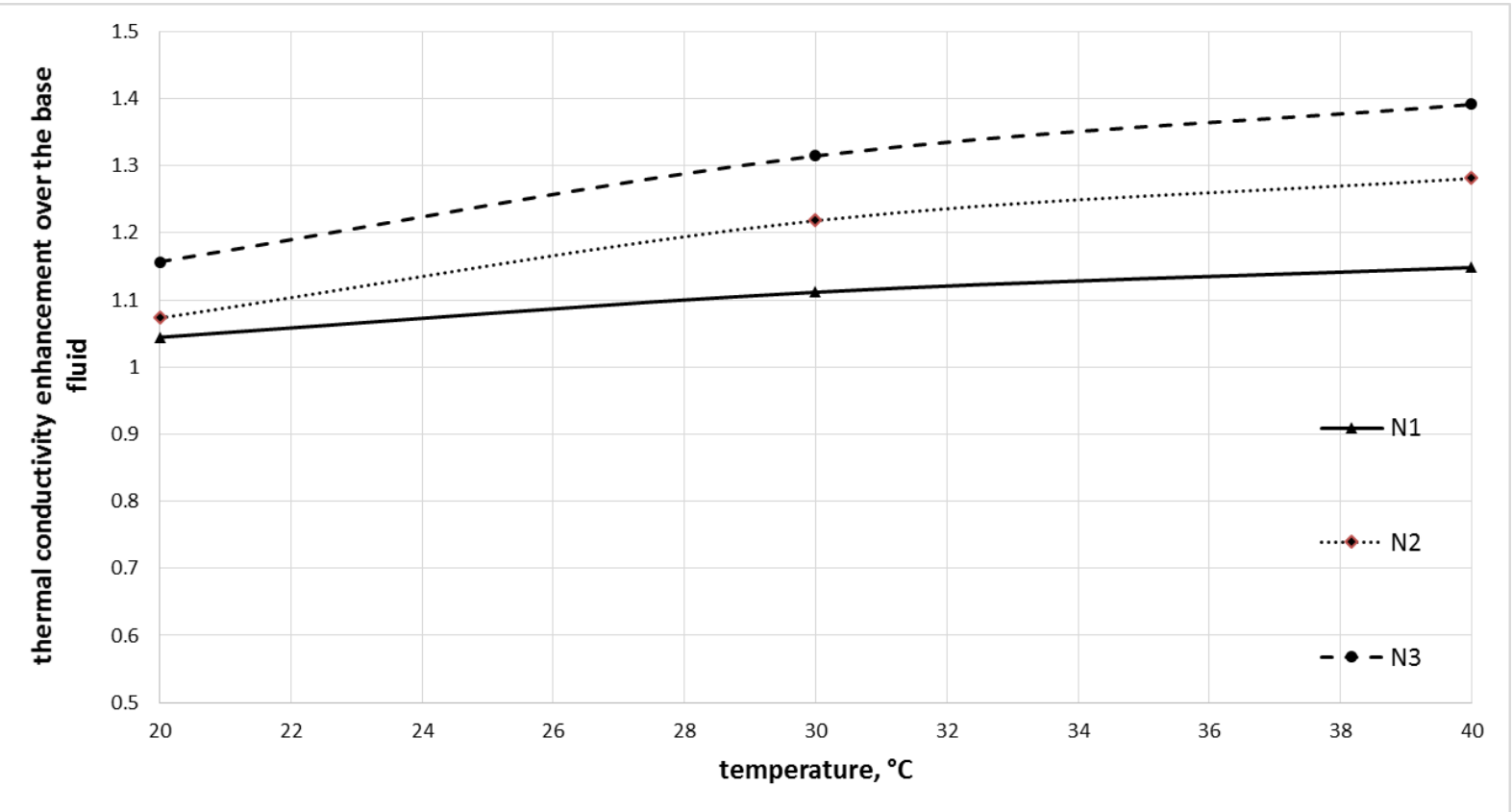

Figure 1. Thermal conductivity enhancement of the CNT nanofluids. 


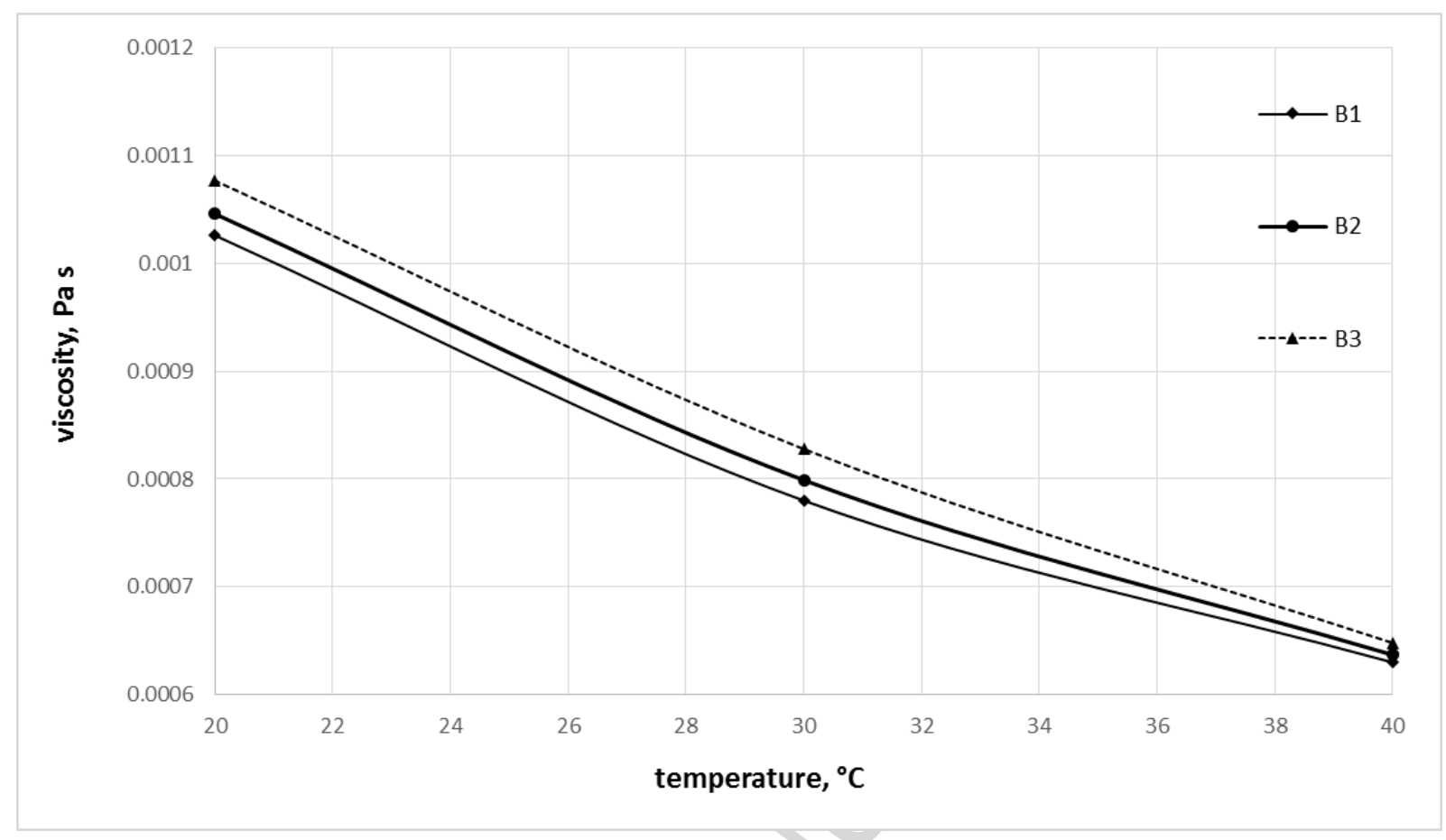

Figure 2. Viscosity of the base fluids (water + SDBS surfactants) at different temperatures 


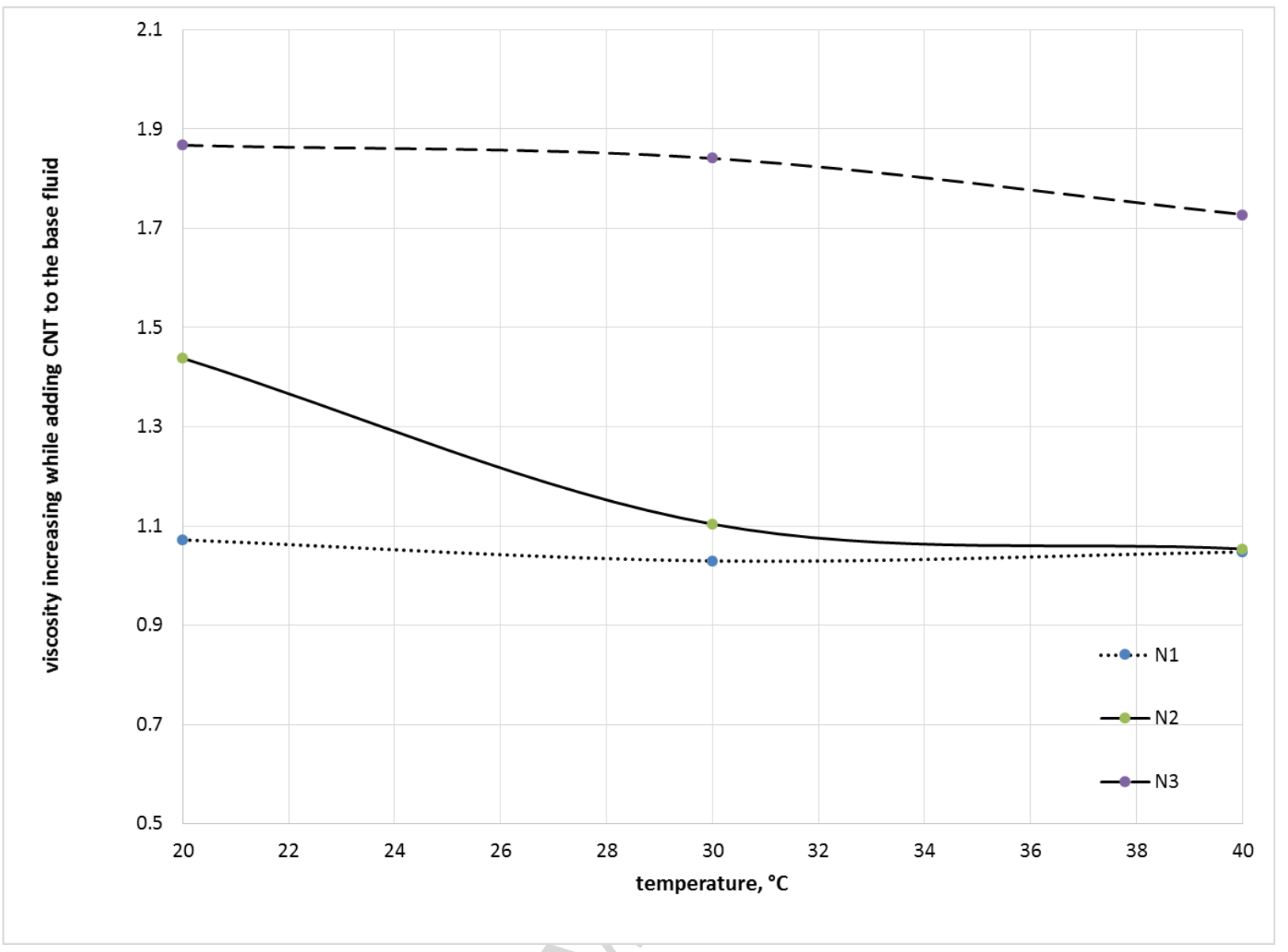

Figure 3. Viscosity variation of the CNT nanofluids over their base fluids. 


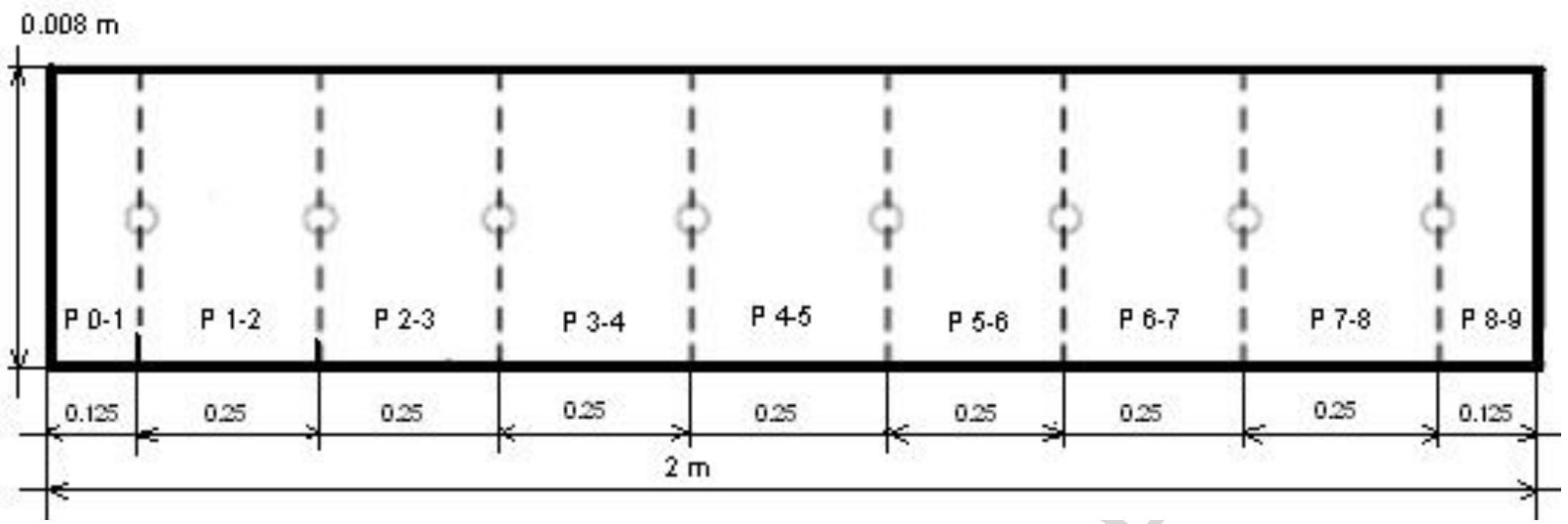

Figure 4. The calculation domain 


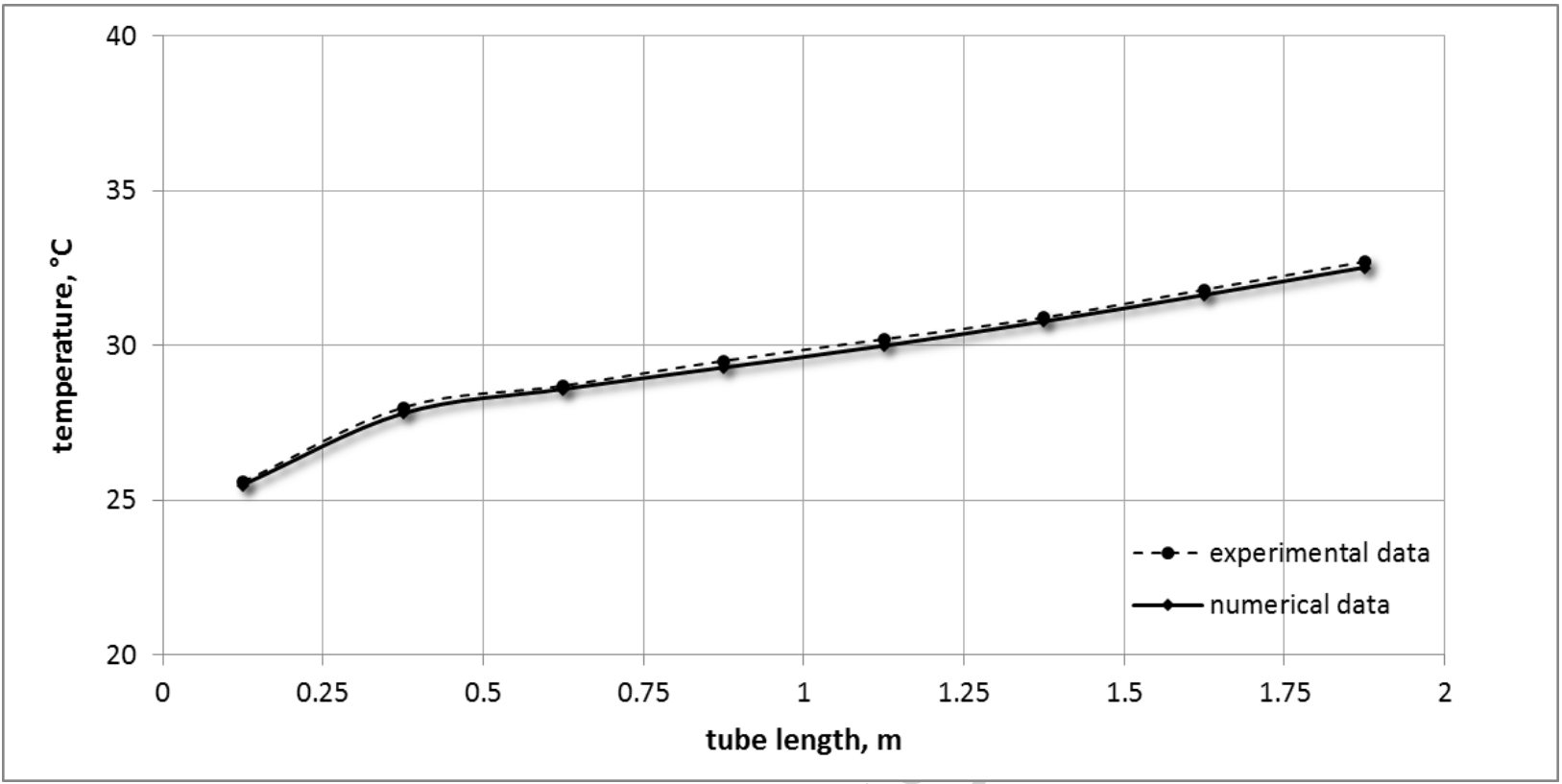

Figure 5. Validation of present discussion 


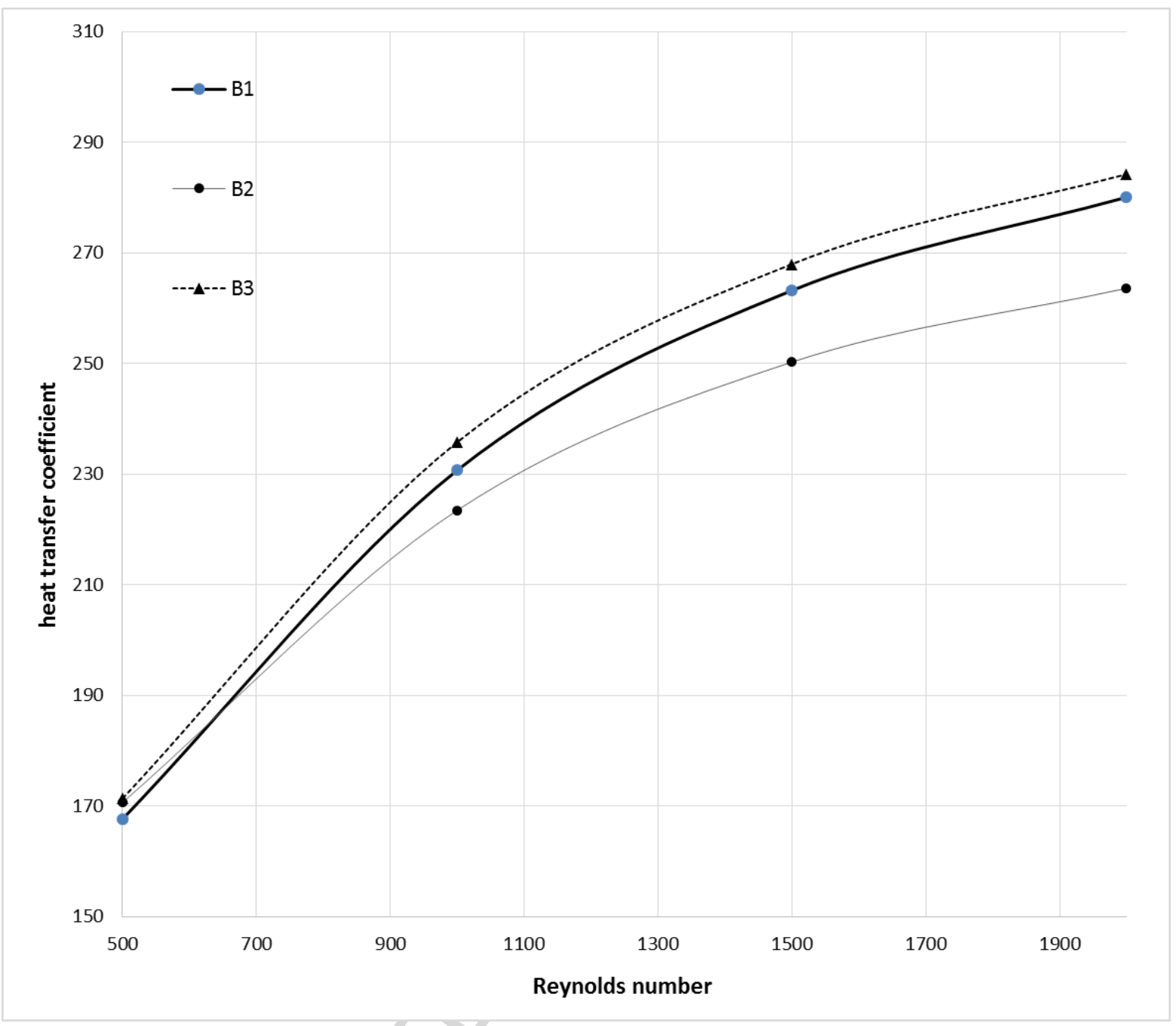

Figure 6. Heat transfer coefficient at $x=1.875 \mathrm{~m}$ from inlet for the base fluids 


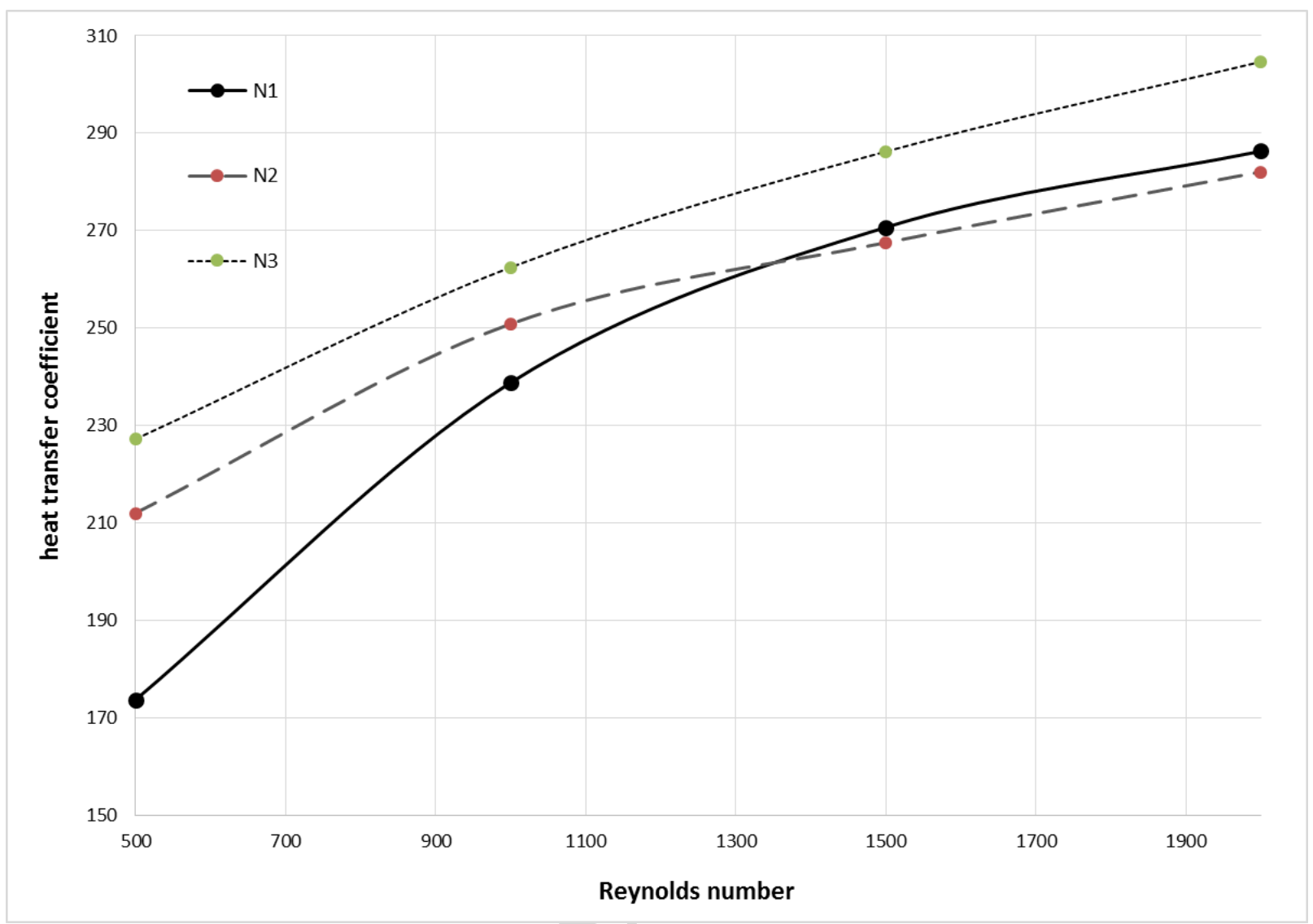

Figure 7. Heat transfer coefficient at $\mathrm{x}=1.875 \mathrm{~m}$ from inlet for the CNT nanofluids 


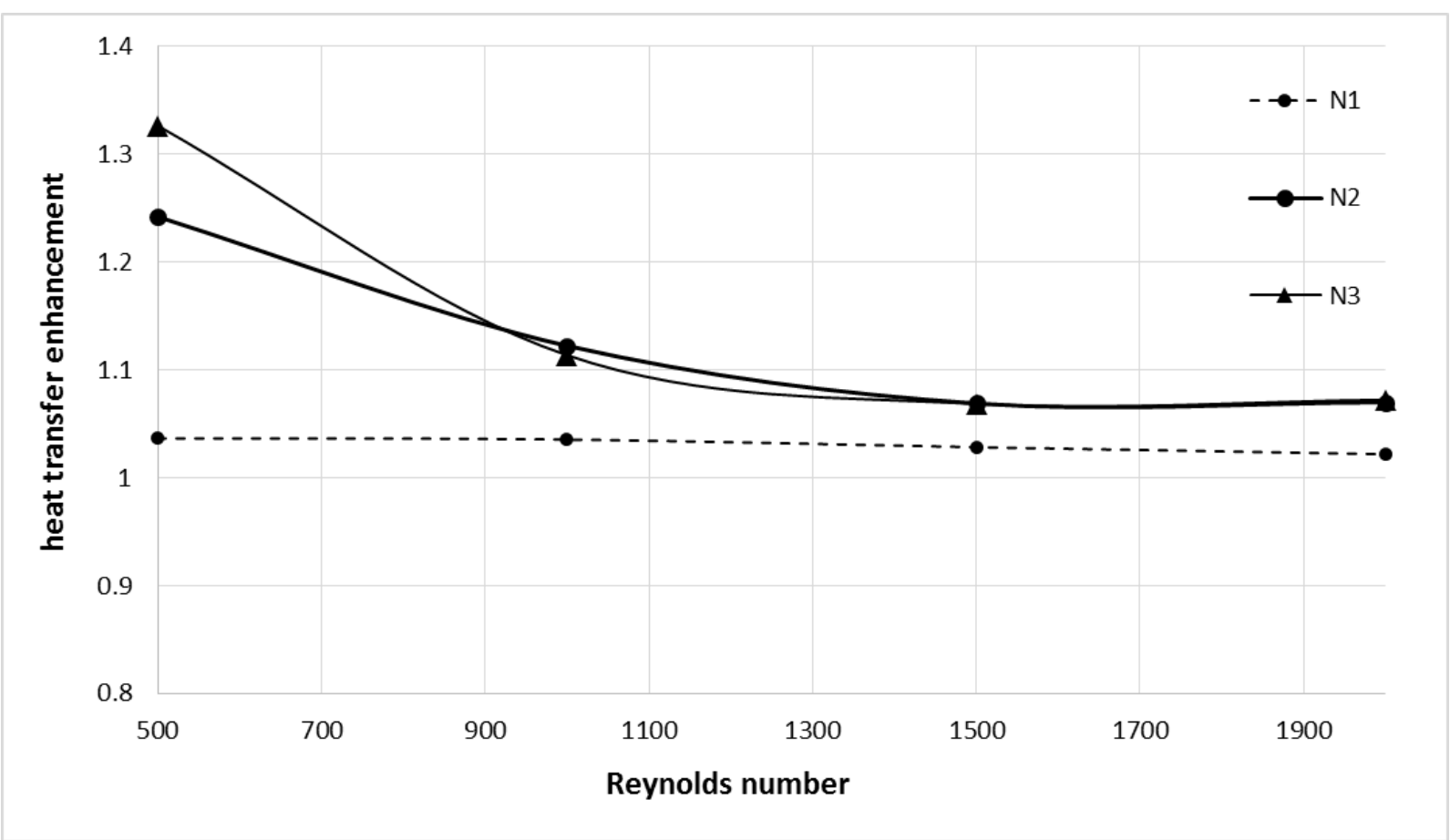

Figure 8. Heat transfer enhancement by adding CNT at the defined base fluids, for a location $\mathrm{x}=1.875 \mathrm{~m}$ in the pipe. 


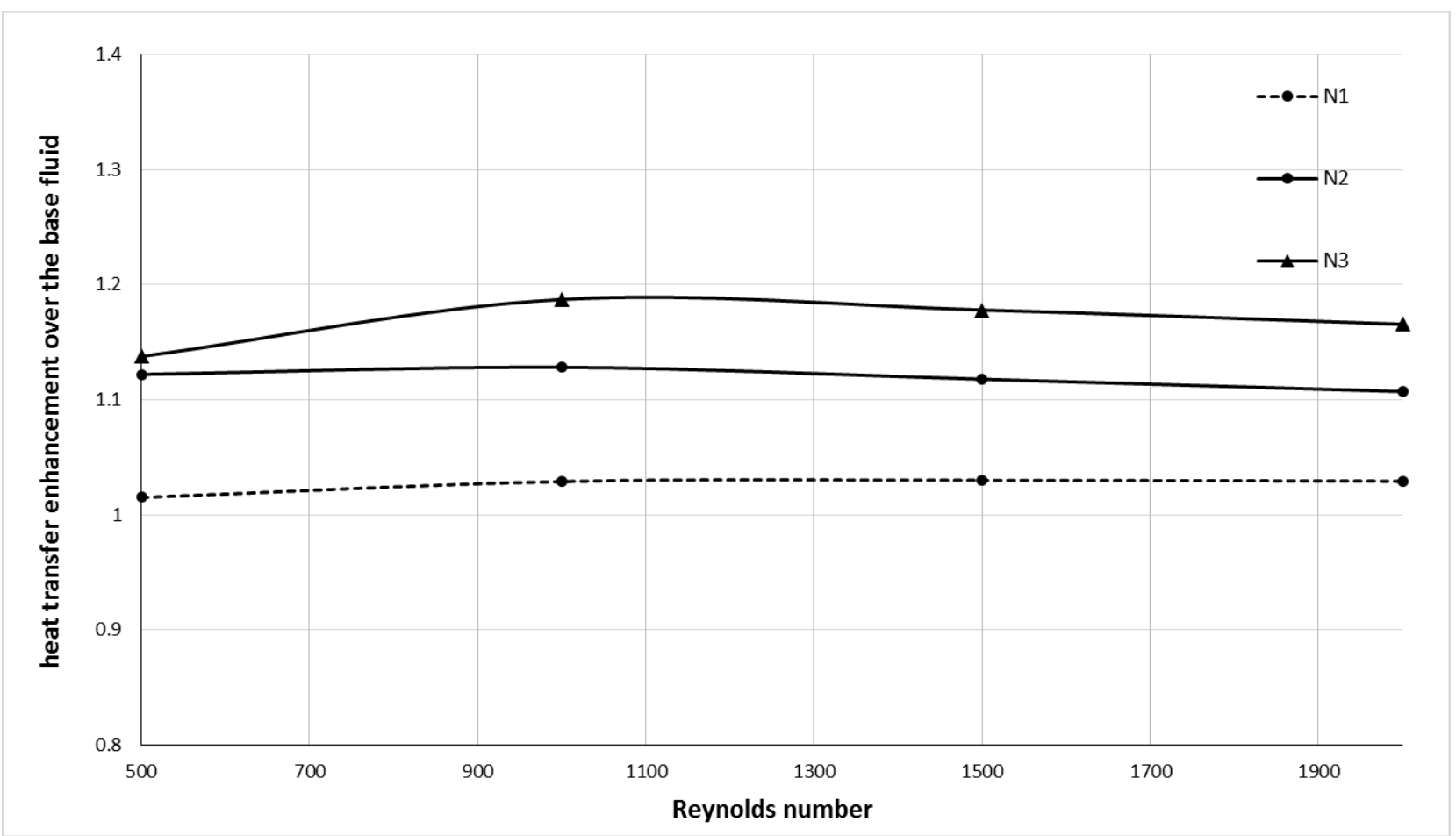

Figure 9. Heat transfer enhancement by adding CNT at the defined base fluids at a location $\mathrm{x}=0.125 \mathrm{~m}$ 


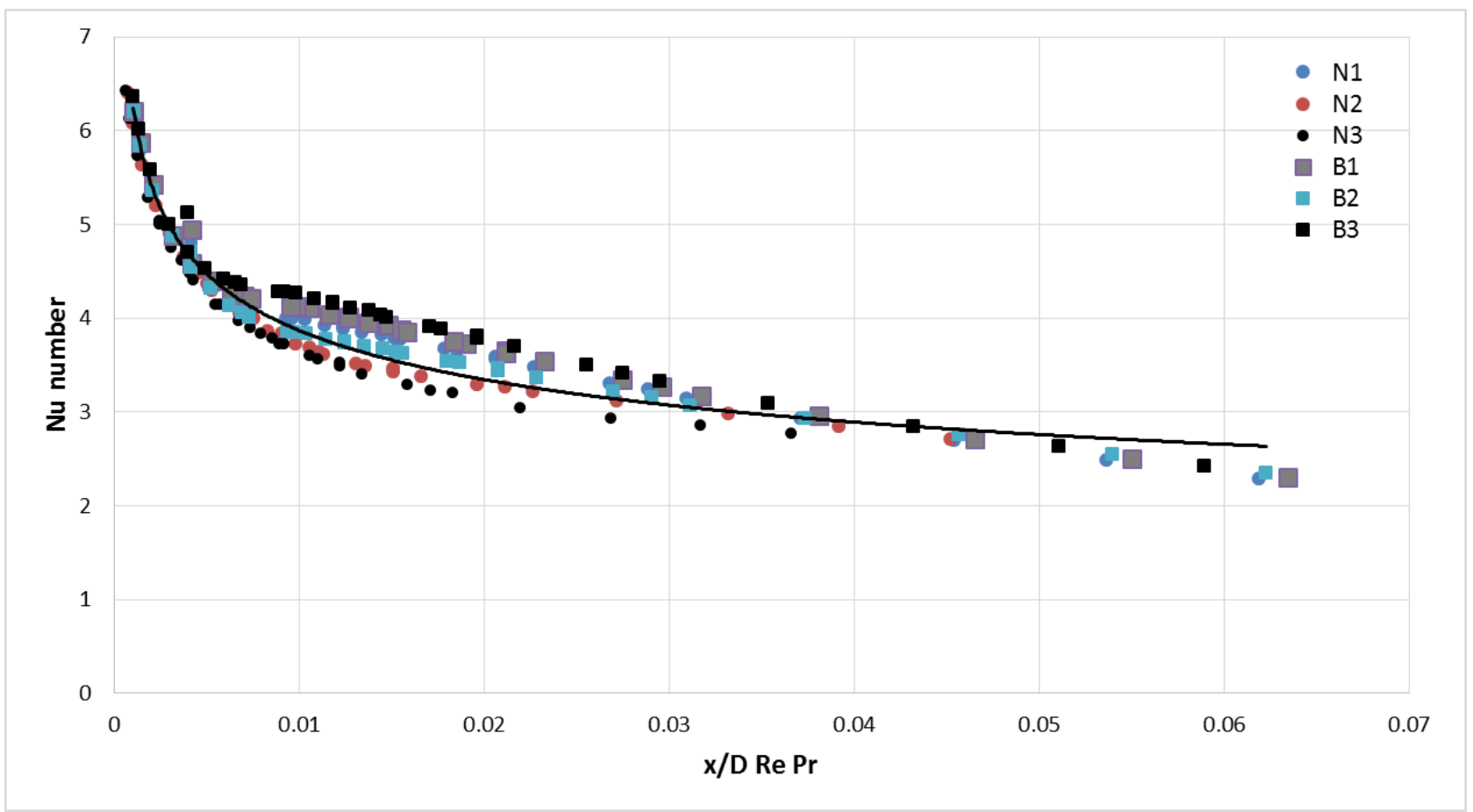

Figure 10. Nu number versus (x / D Re Pr) for all studied fluids - correlation 